\title{
Rival genetics projects build bridges
}

Projects that explore the world's biodiversity might seem like natural allies. But last week a workshop was held in North Carolina expressly to mend fences between two such initiatives that have different approaches.

Both projects use genetics to catalogue the relationships between organisms. The Assembling the Tree of Life project, funded by the US National Science Foundation, explores the evolutionary relationships between different classes of organisms. And the Consortium for the Barcode of Life initiative, funded largely by private foundations, uses short DNA signatures to discriminate between species.

Some systematists, such as those in the Tree of Life project, think that the upstart barcoding approach ignores crucial information that helps to define organisms, such as their habitats and their relationships with other species. As a result, the two groups tend to regard each other with more scepticism than friendliness.

The workshop, which was held on 19-20 April and attended by about 40
"The joint workshop is a signal that a lot of the hostility to genetic barcoding has died down." signal that a lot of the hostility about barcoding has died down and disappeared," says David Schindel, executive secretary of the Barcode of Life project.

But others remain more reserved. "I still have some scepticism about barcoding, depending on what its goals are," says Cracraft.

Proponents of barcoding have scientists from both communities, was intended "to build bridges", says co-organizer Joel Cracraft, an ornithologist at the American Museum of Natural History in New York.

For some, the occasion was a milestone. "This really is a encountered particularly tough resistance to the idea that the technology will help the world to catalogue its fast-disappearing biodiversity, by quickly identifying new species based on DNA differences from known species. Systematists scoff at this idea and say that because species have varying levels of genetic diversity, setting a uniform cut-off for how much diversity distinguishes a

new species is tough.

But barcoders have now published research showing that their approach can work in some contexts (K. C. R. Kerr et al. Molecular Ecology Notes doi:10.1111/ j.1471-8286.2007.01670.x; 2007). And systematists have decided to try to find common focus with barcoders, rather than turning up their nose at the entire enterprise.

The meeting's organizers hope that these connections will ultimately lead to collaborations. But for now, they say, just getting the scientists to talk to each other is a good first step.

Erika Check 